\title{
Survival Strategies and the Growth of Small and Medium Scale Enterprises (SMEs) In Federal Capital Territory (FCT), Abuja
}

\author{
Micah, Ezekiel Elton Michael (Ph.D)* Mohammed Kazeem Adekunle, * Akinwunmi Adeboye (Ph.D)** \\ Department of Business Administration, Nassrawa State University, Keffi-Nigeria* \\ Department of Banking \& Finance, Achievers University, Owo- Nigeria**
}

\begin{abstract}
The business sector is globally characterized as turbulent with huge and constant movement in and out. This is so because the business environment is changing, dynamic, turbulent, discontinuous and highly competitive. In the process, many small and medium scale enterprises (SMEs) deploy diverse practices to gain competitive advantages for their survival. The study thus examines the survival strategies and growth of small and medium scale enterprises (SMEs) in an emerging economy using selected SMEs in Abuja as a study. The empirical analysis was conducted using Ordinary least square (OLS) regression method; while t-test statistic was used to test each of the hypotheses. Findings from the study revealed that product line diversification had no significant effect on business expansion of SMEs. In addition, product branding has had no significant impact on the sales turnover of SMEs for the past few years. However, ideas/innovation was discovered to have a significant impact on the profit margin of SMEs for the past years. It showed the adoption of modern method production had increased their revenue generations. The study thus recommends that the most important strategy that can be used in repositioning SMEs and other micro enterprises in Nigeria is for them to identify the type of products they want to offer to the market. This means a determination of the type of products in which they have distinctive competence to produce. Further development of the technology would make transplantation and adaptation for use in diverse fields of production possible.
\end{abstract}

Keywords: Diversification, Business Expansion, Branding, Small and Medium Scale Enterprises and Sales Turnover

DOI: $10.7176 / \mathrm{EJBM} / 11-30-12$

Publication date:October $31^{\text {st }} 2019$

\section{Introduction}

Small and medium scale industries play a predominant role in most developed and developing countries not only because of their number, variety and involvement in all segments of the economy but more importantly, their role in employment creation (Kongmanila and Takahashi, 2009). This is so because the business environment is changing, dynamic, turbulent, discontinuous and highly competitive. In this period, the relationship between business and society has changed radically. However, the business sector is globally characterized as turbulent with huge and constant movement in and out. Even in years when the economy is performing relatively well, many firms close and many also start up. The operating environment has remained hostile and challenging being characterize by precarious industry settings, intense competition, harsh overwhelming business climates and relative lack of exploitable opportunities.

The struggle to survive is a natural instinct; and as postulated by Darwin (1959), "survival is a constant battle against the environment". It is therefore natural for businesses to struggle against imminent collapse or failure amidst the contextual hostility. In the process, they deploy diverse practices to gain competitive advantage. Absurdly, these responses might not have yielded the right solution to overcome the crisis. Business researchers described the traditional business approaches as inappropriate in this scenario. Scholars such as Smallbone, Kitching and Xheneti (2009) believe that there is no single best practice that guarantees business survival, or success, and that firms adaptation and performance are contingent upon organizational factors such as resources available, and external influences, including product, labour and capital market conditions. In the same vein, Nguyen and Kock (2011) suggested the need for a new perspective that would enhance the understanding of how firms survive in turbulent environments. However, contemporary business scholars such as Mishra (2012) believe that the difference between survival and extinction is more about discipline versus excess; and adaptation versus rigidity.

However, over the years, several problems have been identified to limit the growth, survival of various small and medium scale enterprises (SMEs). This has effectively affected their contribution of to the economic growth of Nigeria. Lack of conducive and enabling macroeconomic policy environment among other problems remains the drawback to the survival, development and growth. 
The SMEs are associated with constant struggle against imminent collapse due to contextual hostility that bedevils the sector. While many of them often die before their fifth anniversary, several others secure their survival by embarking on diverse practices aimed at gaining competitive advantage. Diminishing growth potentials in the economy have further drawn increased attention on the need to study survival strategies and growth of SMEs in Nigeria. The study therefore assessed the impact of survival strategies on the performance of Small and Medium Scale Enterprises (SMEs) using selected SMEs in Abuja as a study.

Small and Medium Scale Enterprises are very vulnerable, and their failure rate is very high; so high that no nation can afford to ignore it. It was observed that " 60 per cent of small business fails in the first three years of existence in many African countries. In Nigeria, the picture is much the same with "eighty percent of all start-ups succumb within their first five years". Nigerian Economic Summit Group (2012) also emphasis that about 70 per cent of Small Enterprises in Nigeria failed within the first five years of operation. With this being the case, greater efforts are urgently needed to reduce the fatality rate of Small and Medium Scale Enterprises. Ultimately, a more robust SMEs sector will help to build a nation's wealth, without it having to woo investments of sophisticated technology.

The study thus provided answers to the following questions:

i) What effect does product line diversification has on business expansion of SMEs?

ii) To what extent has branding has impacted on the sales turnover of SMEs

iii) What influence does Ideas/Innovation has on the profit margin of SMEs?

In-line with these problems, the following hypothesis were tested:

Ho1: Product line diversification has no significant effect on business expansion of SMEs

H02: Product branding has not impact on the sales turnover of SMEs

H03: Ideas/Innovation has no significant impact on the profit margin of SMEs.

\section{Conceptual Framework}

\section{Concept of Survival Strategies}

Strategy is the set of long - term choices the small and medium business leaders make in terms of goals, services, policies and action plans (Adeyemi \& Aremu, 2011). Successful strategies must meet both the broad business objectives set by government and by the environment. For example, a governmental programme to promote small scale industries throughout the country must have goals and services consistent with the literacy and background of potential entrepreneur, the potential demand for various goods and gaps in the infrastructure. Strategies that meet the government's objectives and match the environment are more likely to succeed than those that do not (Moriam, Mukaila and Hameedat, 2015).

According to Brody et al, (2007) small businesses have been found to be more likely to succeed when they follow certain core practices such as: maintain a focus on markets and customers by developing products or services that offer a clear competitive advantage; develop their workforce through training and/or human resources services; and forge innovative partnership by working with partners - especially those in the private sector - to achieve their goals. Thus, it can be concluded that business survival strongly depends on the ability of the owner/manager to integrate, build, and reconfigure internal and external competences of the business to address rapidly changing environments'.

\section{Concept of SMEs}

Small and medium enterprises (SMEs) have continued to be a popular phrase in the business world, and thus occupy a place of pride in virtually every country. This is because of the significant role SMEs play as the mainstay of the economic activities in terms of employment generation, national growth, poverty reduction and economic development of global economies including Nigeria. In towns and cities, these businesses employ large percentage of the population. According to Kadiri (2012) cited in Peterise (2003), SMEs both in the formal and informal sectors employ over $60 \%$ of the labor force in Nigeria. More so, $70 \%$ to $80 \%$ of daily necessities in the country are not high tech products, but basic materials produced with little or no automation. Records have shown that SMEs have in many countries provided the mechanism for stimulating private ownership and entrepreneurial skills, enhancing greater employment opportunities per unit of capital invested and aiding the development of local technology (Sule, 1986; Justin, 2014). 
Supporting the view above, Ajose (2010) states that SMEs are the pivot of economic growth and first point of contact for the business world. SMEs help to mobilize savings for investment and promote the use of local raw materials. They help diversify economic activity and make significant contribution to exports and trade. SMEs are also important for poverty reduction as they tend to employ poor and low income workers and sometimes they are the source of employment in rural areas and poor regions. Furthermore, by producing intermediate products for use in large enterprises, SMEs contribute to the strengthening of industrial linkages. These explain the increased interest which developing countries have shown in the promotion of SMEs since the 1970s (Ekpenyong and Nyong, 1992). According to Bonga (2010), many economies have lagged behind in the promotion of SMEs and have missed the benefits they bring in a nation. Rather, nations have been supporting large scale projects and large companies, which is a good policy but not enough for maximum development of the nations.

SMEs spring up in towns and cities almost on a daily basis. No sooner are they established that they fold up mostly within the first few years of operation. What is responsible for this? Several problems limit the growth, survival and hence effective contribution of SMEs to the economic growth of Nigeria. Lack of conducive and enabling macroeconomic policy environment among other problems remains the drawback to the survival, development and growth of SMEs (Obitayo, 2001).

\section{Theoretical Framework}

The Dynamic Capability Theory (DCT): The theory of Dynamic Capability has its foundation in Ricardian economics (Peteraf, 1993). It was first introduced in 1994 by David Teece and Gary Pisano to explain firm performance in dynamic business environment, focusing on the capabilities that firms employ to reach competitive advantage (Beske, Land and Seuring, 2014). It adds to the Resource Base View (RBV) by explaining the nature of sustainable competitive advantage, while also intending to inform managerial practices. It emphasized the key role of managers in appropriately adapting, integrating and reconfiguring resources and competences to match the market change (Teece and Pisano. 1997). The framework was later on developed as an extension of the RBV to address dynamic markets; i.e. DCT seeks to explain how business firm achieve and sustain competitive advantage despite an ever-changing environment.

Scholars define dynamic capability as 'the firm's ability to integrate, build, and reconfigure internal and external competences to address rapidly changing environments'. DCT can be disaggregated into three distinct processes corresponding to three stages of building dynamic capabilities: sensing, seizing and reconfiguring (Teece, 2007). Sensing refers to the ability of the business firm to identify opportunities in a fast-paced, competitive environment, where consumer needs are constantly changing. To be able to do this, the business firm needs to constantly scan, search and explore new market. The firm would also need to invest in research activities; business intelligence to monitor customer and supplier needs; and technology possibilities,

Seizing opportunities refers to the managerial ability to establish strategic decision making rules and resource allocation processes. In the business organisation, this is done by taking the risk of introducing new products, processes or services to the market which requires investments in development and commercialization activities (Teece, 2007). This will require the business firm to improve its technological competence and complementary assets, so that it secures early entry into the market as soon as the opportunity is ripe.

It has been criticized as lacking in clear theoretical foundation (Arend and Bromiley, 2009), which can limit "fruitful conversation", hamper progress, prevent empirical research (Stefano et al., 2010). Again, the theory only explains how change occurs through learning and reconfiguring but does not explain when an organization does not change. It also lacks clarity in terms of its most basic aspects including how they are defined. Finally, the theory has also been faulted for lacking in exact definitions, measurability and other necessities that can enable the development and assessment of hypotheses and predictions (Pavlou and El Sawy, 2011)

Despite the criticisms, the DCT has been one of the most active areas of research in the field of strategic management. It has been published in business and management journals at a rate of more than 100 per year (Di Stefano et al, 2010). This has also led it to be a very vibrant field with a large scope (Ibid). Zahra, Sapienza, and Davidsson (2016) added that the theoretical and practical importance of DC's in explaining competitive advantage in different market environments, has led to wide interest in the approach.

Nevertheless, with regards to manufacturing business firms, success is largely dependent upon the ability to make use of the dynamic capabilities that are embedded within the business processes, positions and path; to sense and shape opportunities and threats, to seize opportunities and to maintain competitiveness through enhancing, 
combining, protecting, and when necessary, reconfiguring the businesses intangible and tangible assets. Continual innovation is therefore, a necessary attribute of the small business owner.

\section{Empirical Reviews}

Umar (2005) explored the impact of survival strategies as a tool of achieving an effective and efficient merger and acquisition at Nestle and Lever Brothers Plc. Based on the findings of the study, it was concluded that strategic diversification played a very important role in the success, growth and survival of the company, particularly where merger was concerned.

Dauda, Akingbade and Akinlabi (2010) examined the influence of product branding on corporate performance in selected small-scale enterprises in Lagos Metropolis, Nigeria. Their findings revealed that strategic branding practices enhance both organizational profitability and company market share and it was concluded that product branding practices enhance both organizational profitability and company market share and therefore suggest that strategic planning concepts should be adopted by business organizations.

Fiberesima and Abdul Rani (2013) examined the impact of innovation on business success in Nigeria. The study concluded that innovation was found to be positively related to corporate success, and innovation practices improve business success.

Gichunge (2007) examined the effect of formal innovation on organizational performance of medium sized manufacturing enterprises in Nairobi, Kenya. One of his key findings is that competition influences adoption of formal strategic innovation, this is even as it was discovered that organizations with formal innovative choices performed better than those without formal innovative choices.

Singh (2005) in his studies examined the impact of strategic planning process variation on superior organizational performance in non-profit human service organizations providing mental health services. The major finding of this study was that strategic planning is highly correlated with superior organizational performance.

Askarany and Yazdifar (2012) in their studies investigated the diffusion of six proposed strategic choices tools of the past few decades through the lens of organizational change theory, examined the relationship between the adoption of these techniques and organizational performance in both manufacturing and non-manufacturing organizations in New Zealand. The results and findings showed a significant association between the diffusion of these relatively new strategic choices tools and organizational performance.

Muogbo (2013) explored the impact of business diversification on organizational growth and development of selected manufacturing firms in Anambra State in Nigerian. Results from the analysis indicated that the adoption of business diversification has significant effect on competitiveness and significant effect on employee's performance and has significantly increased organizational productivity.

Andrews et al. (2006) examined the relationship between strategic location and organizational performance in a multivariate model that also controls for external constraints. Their measures of prospecting, defending, and reacting were based on Likert scale survey responses from senior and middle managers in a sample of 120 organizations. The empirical results reveal a hierarchy of strategy types: the impact of prospecting is positive, defending is neutral, and reacting negative.

\section{Research Methodology}

Descriptive survey research design was adopted for this study. The descriptive design describes phenomena as they exist. It issued to identify and obtain information on the characteristics of a particular problem or issue. Descriptive research design was selected because it has the advantage of producing good amount of responses from a wide range of people. Also, this design provides a meaningful and accurate picture of events and seeks to explain people's perception and behavior on the basis of the data collected. The advantage with this design is that it helps to find views as they are in their natural setting.

The population of the study consists of selected SMEs in FCT, Abuja. A sample of 121 SMEs was drawn up using Smith (1984) sample size formula out of 523 populations. A self-administered questionnaire of 185 was used in gathering the data, out of which 121 were properly filled and returned. 
Table 1: A Selected sample of Surveyed SMEs in FCT, Abuja

\begin{tabular}{cccc} 
S/N & Categories of SMEs & $\begin{array}{c}\text { Population of } \\
\text { SMEs Per } \\
\text { Location }\end{array}$ & Sampled Per Location \\
\hline 1 & Jikwoyi & 87 & $\frac{121 * 87}{523}=20$ \\
2 & Nyanya & 131 & $\frac{121 * 131}{523}=30$ \\
3 & Gwagwalada & 305 & $\frac{121 * 305}{523}=71$ \\
Total & & $\mathbf{5 2 3}$ & $\mathbf{1 2 1}$ \\
\hline
\end{tabular}

Source: Field Survey, 2018

A five point Likert scale of agree to disagree (that is, Agreed, Disagree, Undecided, Strongly Agreed and Strongly Disagreed) was used to measure the extent to which the various respondents agreed or disagreed with the issues raised.

Ordinary least square (OLS) regression method of data analysis was adopted for the study. The model specifications here are formulated to tests the three hypotheses and they are as follows:

$$
\begin{aligned}
& B E=\beta_{0}+\beta_{1} P L D+\mu_{t}-------1 \\
& S T=\beta_{0}+\beta_{2} P B+\mu_{t}---------2 \\
& P R=\beta_{0}+\beta_{2} I N+\mu_{t}---------3
\end{aligned}
$$

Where;

$\mathrm{BE} \quad=\quad$ Business expansion

$\mathrm{PLD}=$ Product line diversification

$\mathrm{ST}=$ sales turnover

$\mathrm{PB} \quad=\quad$ Product branding

PR $\quad=\quad$ Profit

IN $=$ Ideas/Innovation

$\mu_{t} \quad=\quad$ Error term

\section{Results and Discussion}

Statistical Test of Hypotheses

In line with the statistical research, the three hypotheses formulated in this paper were approached with the aid of independent sample $t$-statistics. The level of significance for the study is $5 \%$, for a two-tailed test and it is suggested that we shall go with the null hypothesis if the critical t-value of \pm 1.96 is greater than the estimated value from our analysis, else it will be rejected.

Hypotheses One: H01: Product line diversification has no significant effect on business expansion of SMEs Model one: $B E=\beta_{0}+\beta_{1} P L D+\mu_{t}----------1$ 
Table 2: Regression Result on Product line diversification and business expansion of SMEs

Dependent Variable: BE

Method: Least Squares

Date: 07/13/17 Time: 20:12

Sample: 166

Included observations: 166

\begin{tabular}{lrlll}
\hline \hline \multicolumn{1}{c}{ Variable } & Coefficient & Std. Error & t-Statistic & Prob. \\
\hline \multicolumn{1}{c}{ C } & 2.224623 & 1.410652 & 2.123640 & 0.0013 \\
\multicolumn{1}{c}{ PLD } & 3.855680 & 3.320421 & 1.159301 & 0.4200 \\
\hline \hline R-squared & 0.479309 & Mean dependent var & 13.98708 \\
Adjusted R-squared & 0.457493 & S.D. dependent var & 1.542254 \\
S.E. of regression & 1.052251 & Akaike info criterion & 3.000201 \\
Sum squared resid & 33.21694 & Schwarz criterion & 3.091810 \\
Log likelihood & -46.00322 & Hannan-Quinn criter. & 3.030567 \\
F-statistic & 11.32405 & Durbin-Watson stat & 2.019083 \\
Prob(F-statistic) & 0.000001 & & \\
\hline \hline
\end{tabular}

Source: Authors Computation, 2017 (Eview-10)

$$
\begin{aligned}
& B E=2.22+3.85 P L D-------------2 \\
& S E E=1.41 \quad 3.32 \\
& t^{*}=2.12 \quad 1.15 \\
& F^{*}=11.32 ; \text { Prob(F-statistic) }=0.0002 \\
& R^{2}=0.4793 ; \text { Adj. } R^{2}=0.4574 \\
& D W=2.01
\end{aligned}
$$

Test of Hypotheses One: $\mathrm{H}_{01}$

From the regression result in table 2, it was observed that the calculated t-value for Product line diversification is 1.15 and whilst the tabulated value is 1.96 . Since the t-calculated is greater than the t-tabulated $(1.15<1.96)$ it thus falls in the acceptance region and hence, we reject the first null hypothesis $\left(\mathbf{H O}_{1}\right)$. The conclusion here is that Product line diversification has no significant effect on business expansion of SMEs.

\section{The ANOVA F-statistic}

The F-statistics which is used to examine the overall significance of regression model equally showed that the result is significant, as indicated by a very high value of the $F$-statistic, 11.32 and it is significant at the 5.0 per cent level. That is, the F-statistic p-value of 0.0002 is less than 0.05 .

\section{$\underline{\text { The }} R^{2}$ (R-square)}

The coefficient of determination (R-square), used to measure the goodness of fit of the estimated model, indicates that the model has a poor fit in prediction. The $R^{2}$ (R-square) value of 0.4793 shows that Product line diversification has a poor impact on branch business expansion of SMEs. It indicates that about 47.93 per cent of the variation in branch business expansion of SMEs is explained by product line diversification, while the remaining unaccounted variation of 52.07 percent is captured by the white noise error term

\section{Serial correlation}

Durbin Watson $(D W)$ statistic was used to test for the presence of serial correlation or autocorrelation among the error terms. The model also indicates that there is no autocorrelation among the variables as indicated by Durbin Watson (DW) statistic of 2.01. This shows that the estimates are unbiased and can be relied upon for policy decisions.

Hypotheses Two: H02: Product branding has not impact on the sales turnover of SMEs for the past few years. Model Two: $S T=\beta_{0}+\beta_{2} P B+\mu_{t}---------3$ 
Table 3: Regression Result on Product branding and sales turnover of SMEs for the past few years

Dependent Variable: ST

Method: Least Squares

Date: 07/13/17 Time: 20:15

Sample: 166

Included observations: 166

\begin{tabular}{lrlll}
\hline \hline \multicolumn{1}{c}{ Variable } & Coefficient & \multicolumn{1}{c}{ Std. Error } & t-Statistic & Prob. \\
\hline \multicolumn{1}{c}{ C } & 3.113057 & 1.146125 & 2.716158 & 0.0000 \\
\multicolumn{1}{c}{ PB } & 3.208596 & 3.286106 & 0.977136 & 0.4412 \\
\hline \hline R-squared & 0.493685 & Mean dependent var & 13.11850 \\
Adjusted R-squared & 0.461395 & S.D. dependent var & 0.885941 \\
S.E. of regression & 0.712952 & Akaike info criterion & 2.221655 \\
Sum squared resid & 15.24900 & Schwarz criterion & 2.313264 \\
Log likelihood & -33.54649 & Hannan-Quinn criter. & 2.252021 \\
F-statistic & 16.86868 & Durbin-Watson stat & 1.918137 \\
Prob(F-statistic) & 0.000104 & & \\
\hline \hline
\end{tabular}

Source: Authors Computation, 2017 (Eview-10)

$S T=3.11+3.20 P B$

$S E E=1.143 .28$

$t^{*}=3.01 \quad 0.97$

$F^{*}=16.86 ; \operatorname{Prob}(\mathrm{F}$-statistic $)=0.0001$

$R^{2}=0.7936 ;$ Adj. $R^{2}=0.6613$

$D W=1.91$

\section{Test of Hypotheses Two: $\mathrm{H}_{02}$}

From the regression result in table 3 the calculated t-value for Product branding is 0.97 and the critical value is 1.96 under $95 \%$ confidence level. Since the t-calculated is less than the critical value $(0.97<1.96)$ it also falls in the acceptance region and hence, we will accept the second null hypothesis $\left(\mathbf{H O}_{2}\right)$. The conclusion here is that Product branding has no significant impact on the sales turnover of SMEs.

\section{$\underline{\text { The F-statistic }}$}

The F-statistics equally showed that the overall result is significant, as indicated by the value of the $F$-statistic, 16.86 and it is significant at the 5.0 per cent level. That is, the F-statistic p-value of 0.0001 is less than 0.05 .

\section{The $R^{2}$ (R-square)}

Furthermore, the coefficient of determination (R-square), used to measure the goodness of fit of the estimated model, indicates that the model is also not reasonably fit in prediction. The $R^{2}$ (R-square) value of 0.4936 shows that Product branding had a poor impact on sales turnover of SMEs for the past few years. It indicates that about 49.36 per cent of the variation in sales turnover of SMEs for the past few years is explained by product branding, while the remaining unaccounted variation of 50.64 percent is captured by the white noise error term.

\section{Serial correlation}

The model also indicates that there is no autocorrelation among the variables as indicated by Durbin Watson (DW) statistic of 1.91. This shows that the estimates are unbiased and can be relied upon for policy decisions.

Hypotheses Three: H03: Ideas/Innovation has no significant impact on the profit margin of SMEs Model three: $P R=\beta_{0}+\beta_{2} I N+\mu_{t}---------5$ 
Table 4: Regression Result on Ideas/Innovation and profit margin of SMEs

Dependent Variable: PR

Method: Least Squares

Date: 07/13/17 Time: 20:18

Sample: 166

Included observations: 166

\begin{tabular}{lrlrl}
\hline \hline \multicolumn{1}{c}{ Variable } & Coefficient & Std. Error & t-Statistic & Prob. \\
\hline \multicolumn{1}{c}{ C } & 11.12581 & 2.223053 & 5.211301 & 0.0000 \\
\multicolumn{1}{c}{ IN } & 4.191668 & 1.878393 & 2.231518 & 0.0011 \\
\hline \hline R-squared & 0.725516 & Mean dependent var & 14.22460 \\
Adjusted R-squared & 0.677039 & S.D. dependent var & 1.493695 \\
S.E. of regression & 1.488428 & Akaike info criterion & 3.702068 \\
Sum squared resid & 57.60090 & Schwarz criterion & 3.797225 \\
Log likelihood & -49.82895 & Hannan-Quinn criter. & 3.731158 \\
F-statistic & 12.201412 & Durbin-Watson stat & 1.983246 \\
Prob(F-statistic) & 0.0001257 & & \\
\hline \hline
\end{tabular}

Source: Authors Computation, 2017 (Eview-10)

$$
\begin{aligned}
& P R=11.12+4.19 I N--------------6 \\
& S E E=2.22 \quad 0.11 \\
& t^{*}=5.21 \quad 2.23 \\
& F^{*}=12.20 ; \text { Prob }(\text { F-statistic })=0.00012 \\
& R^{2}=0.7255 ; \text { Adj. } R^{2}=0.6770 \\
& D W=2.12
\end{aligned}
$$

Test of Hypotheses Three: $\mathrm{H}_{03}$

The calculated t-value for Ideas/Innovation was found to be 2.23 and also by rule of thumb, the tabulated value is \pm 1.96 under $95 \%$ confidence interval levels. The calculated t-value for Ideas/Innovation is found to be greater than the tabulated value (that is; $2.23>1.96)$, we thus, reject the third null hypotheses $\left(\mathrm{H}_{3}\right)$ and conclude that Ideas/Innovation had a significant impact on the profit margin of SMEs

\section{The F-statistic}

The F-statistics which is also used to examine the overall significance of regression model equally showed that the result is significant, as indicated by a very high value of the $F$-statistic, 12.20 and it is significant at the 5.0 per cent level. That is, the F-statistic p-value of 0.0012 is less than 0.05 .

\section{$\underline{\text { The }} R^{2}$ (R-square)}

The coefficient of determination (R-square), used to measure the goodness of fit of the estimated model, indicates that the model is reasonably fit in prediction. The $R^{2}$ (R-square) value of 0.7255 shows that Ideas/Innovation has a strong impact on profit margin of SMEs for the past years. It indicates that about 72.55 per cent of the variation in profit margin of SMEs for the past years is explained by Ideas/Innovation, while the remaining unaccounted variation of 27.45 percent is captured by the white noise error term

\section{Serial correlation}

The model also indicates that there is no autocorrelation among the variables as indicated by Durbin Watson (DW) statistic of 1.98. This shows that the estimates are unbiased and can be relied upon also for policy decisions.

\section{Discussion of Findings}

Findings from the study revealed that product line diversification has no significant effect on business expansion of SMEs. This contrary to the findings of Umar (2005) whose findings showed that strategic diversification played a very important role in the success, growth and survival of the company, particularly where merger was concerned. Furthermore, Muogbo (2013) analysis indicated that the adoption of business diversification has significant effect on competitiveness and significant effect on employee's performance and has significantly increased organizational productivity. 
In addition, product branding has not impact on the sales turnover of SMEs for the past few years. This contradicts the works Dauda, Akingbade and Akinlabi (2010) who study revealed that strategic branding practices enhance both organizational profitability and company market share and it was concluded that product branding practices enhance both organizational profitability and company market share and therefore suggest that strategic planning concepts should be adopted by business organizations. More so, Gichunge (2007) key findings was that innovation influences competition, it was discovered that organizations with formal innovative choices performed better than those without formal innovative choices.

Ideas/Innovation has a significant impact on the profit margin of SMEs for the past years. This agrees with the findings of Owolabi and Makinde (2012) whose results revealed that there was a significant positive correlation between ideas and corporate performance.

\section{Conclusion and Recommendations}

The reality of global competition is a key factor in every business everywhere. Clearly the challenge today for business enterprises especially SME is to formulate strategies that will enable them survive in the new market forces created by the spread of global competition. Faced with these challenges, it is necessary for the manufacturing firms in Nigeria to brace up for globalization move which has opened up international trade liberalization. The manufacturing firms should get over the marriage of problems confronting the sector so as to ensure that their products remain competitive in the world market. This calls for repositioning strategy, to develop new technology and obtain the pertinent information about the operations of the international markets. A strategic sector of the economy such as the micro-enterprises needs to remain competitive to justify its relevance in the economic development process of Nigeria. This can only be achieved by confronting the challenges and realities of contemporary globalization process.

The study thus recommends the following:

i) The most important strategy that can be used in re-positioning of SMEs and other micro firms in Nigeria is for them to identify the type of products they want to offer to the international market. This means a determination of the type of products in which they have distinctive competence to produce. This will require an analysis of the strength and weakness of the enterprises. Having identified the type of products to produce then the manufacturing firms will determine what is required to produce them.

ii) Technology acquisition: there is the need for technology acquisition which is the whole body of the most efficient technical and organizational knowledge and information available for the production of goods and services together with the tools for achieving production. This implies ready access to a technical knowledge for the production of goods and services and control over such technical knowledge. With these capabilities, the SMEs and other micro-firms would be able to respond creatively through product design changes to changes in market conditions using the acquired technology. Further development of the technology would make transplantation and adaptation for use in diverse fields of production possible.

iii) Acquisition of Managerial capability: SMEs and other micro firms need to acquire skilled labour force, managerial ability, and skill for integration and different business activities, the technical ability, of labour, the quality of management and efficiency in the use of labour all contribute to competitive enhancement in the global market

\section{References}

Ajose, S. (2010). SMEs and the tough terrain of Business, Personal Finance and Entrepreneurship. Publication of the Nation Newspaper, Vol.5, No.1547, Oct. 13, p 38.

Andrews, Rhys, George A. Boyne, and Richard M. Walker (2006). Strategy Content and Organizational Performance: An Empirical Analysis. Public Administration Review 66:52-63.

Beske, P., Land, A., \&Seuring, S. (2014). Sustainable Supply Chain Management Practices and Dynamic Capabilities in the Food Industry: A Critical Analysis of the Literature. International Journal of Production Economics, 152, 131-143. doi: 10.1016/j.ijpe.2013.12.026

Bonga, W.G. (2010). Economic Development through Promotion of SMEs. Financial Gazette, Wednesday, 24 February. 
Darwin, C. M. A., (1959); 'On the Origin of Species by Means of Natural Selection, or the Preservation of Favoured Races in the Struggle for Life', London; Edited and annotated by DannSiems (2007)

Dauda, A.Y., Akingbade, A.W., and Akinlabi, B.H. (2010) Strategic Management Practice and Corporate Performance of Selected Small Business Enterprises in Lagos Metropolis. International Journal of Business and Management, 5(11): 97-105.

Ekpeyong, D.B. and. Nyong, M.O (1992). Small and Medium Scale Enterprises Development in Nigeria. Seminar paper on Economic Policy Research for Policy Design and Management in Nigeria.

Eneh, O. C. (2010). Survival Strategies for Entrepreneurs in Dwindling Nigerian Economy, Asian Journal of Industrial Engineering, 2(2):52-62.

Hill, C.W.L. (2005). International Business: Competing in the Global Marketplace. 5th Edition. New York: McGraw-Hill Companies Inc

Justin I.I. (2014). Evaluation of Survival Strategies of Small and Medium Enterprises in Benue State, Nigeria. International Journal of Academic Research in Accounting, Finance and Management Sciences. Vol. 4, No.2, April 2014, pp. 255-263

Kadiri, I.B. (2012). Small and Medium Scale Enterprises and Employment Generation in Nigeria; the Role of Finance. Kuwait Chapter of Arabian Journal of Business and Management Review; Vol. 1, No. 9.

Kumar, R. S., and Subrahmanya, B. (2007): "Subcontracting relationships of Indian SMEs with global TNCs: Do SMEs gain, How" Journal of Asian Economics, 5 (39).

Moriam, A.A., Mukaila, A.A., and Hameedat, B.O. (2015). Impact of Strategic Management on the Performance of Small and Medium Scale Enterprises (SMEs) in Nigeria. Journal of Sustainable Development in Africa, Vol. 17, No.1, pp. 113-126.

Nguyen, H. L. and Kock, S. (2011). Managing SME's Survival from Financial Crisis in a Transition Economy: A Chaos Theory Approach; Journal of General Management: Vol 27 (I), The Bray Book Press;

Owolabi, A.S., and Makinde, G.O. (2012). The Effect of Strategic Planning on Corporate Performance in University Education: A Study of Babcock University. Kuwait Chapter of Arabian Journal of Business and Management Review, 2(4): 27-44 Lagos. Pp. 50-52

Ozoigbo, B.I. and Chukuezi, C.O. (2011).The impact of multinational corporations on the Nigerian economy. European Journal of Social Sciences, 19 (3).

Singh, K. (2005). The Impact of Strategic Planning Process Variation on Superior Organizational Performance in Nonprofit Human Service Organizations Providing Mental Health Services. Columbia University, ProQuest, UMI Dissertations Publishing. 3174894.

Smallbone, D. and Wyer, P. (2006). Growth and development in the small business, in Carter, S. and Jones-Evans, D. (eds) Enterprise and Small Business: Principles, Practice and Policy, Harlow: Pearson Education

Sule, E.I.K. (1986). Small Scale Industries in Nigeria: Concepts, Appraisal of Government Policies and suggested solutions to identified problems. Economic and Financial Review. Vol.24, No.4, CBN.

Teece, D. J., Pisano, G., \&Shuen, A. (2007). Dynamic Capabilities and Strategic Management. Strategic Management Journal, 18(7), 509-533

Umar, K.A. (2005).The Impact of Strategic Management on Mergers and Acquisitions in a Developing Economy: A Case Study of Nestle and Lever Brothers Plc. Unpublished Master Thesis. Department Of Business Administration, Ahmadu Bello University Zara. 